\title{
Editorial
}

\section{The Antarctic visitor}

Climate change is moving a considerable amount of research into several areas of knowledge that were unexpected, for example Chilean research has a program of funding called FONDAP, awarding a grant at FONDAP-IDEAL CENTER and Instituto Antártico Chileno (INACh). These centers will develop research in areas such as oceanography, ecology, genetics and physiology, especially regarding the response to melting iceberg "freshening " and high temperature. Several animal models will be used to discover what will happen in the future as a result of climate change.

Nearly every day, a news report focuses on the changes in the environment and how high temperatures are changing the behaviour-physiology of animals. Also associated with this phenomena is the rise of new economic activities that are increasingly prosperous such as Antarctic tourism, attracting thousands of tourists every year to the frozen continent, with all the anthropogenic implications that this brings.

Therefore, not only the impact of having more researchers in the Frozen Continent is increasing but also is the tourism. The ever increasing pressure to be there causes effects on birds like penguins which are more and more accustomed to see to humans and interact among them, while sea lions and elephant seals no longer feel that they are in presence of foreign organisms. This somehow causes the animals to change their ethology expecting some tip, especially the birds.

Human pressure from both research and tourism is moving microorganisms such as bacteria to a place where they did not initially exist. In addition, the temperature change could potentially mobilise some species of fish, crustaceans, mollusks and even echinoderms from the American continent to the Antarctic, or some insects such as mosquitoes. This is important because perhaps not only the effects of high temperature must be considered, but also the increase of human visitors to the Frozen Continent, who may be vectors of some of the invertebrates/microorganisms mentioned above.

Although grants are needed for research, in this case we must be aware that our movements will always have a consequence, and now that tourism is an important source of business for some companies we should be careful and take measures so as not to carry uninvited animals (microorganisms-invertebrates) to the White Continent. 
